\title{
Pars plana vitrectomy and internal limiting membrane peeling for macular edema secondary to retinal vein occlusion
}

This article was published in the following Dove Press journal:

Clinical Ophthalmology

4 August 201 I

Number of times this article has been viewed

\section{Nader Baharivand \\ Amirhossein Hariri \\ Alireza Javadzadeh \\ Ebadollah Heidari \\ Karim Sadegi}

Nikookari Eye Hospital, Tabriz University of Medical Sciences, Tabriz, Iran
Correspondence: Amirhossein Hariri Nikookari Eye Hospital, Abbasi St, Tabriz, Iran

Tel +984 II 6577334

Fax +98 4II 6577336

Email amirhh52@gmail.com
Purpose: To evaluate the effects of vitrectomy and internal limiting membrane peeling for treatment of macular edema secondary to retinal vein occlusion (RVO).

Methods: Nine cases of visual loss due to macular edema caused by central retinal vein occlusion or branch retinal vein occlusion underwent pars plana vitrectomy with removal of the preretinal hyaloid, peeling of the internal limiting membrane stained with indocyanine green dye, air-fluid exchange, and postoperative prone positioning. Best-corrected visual acuity (BCVA) and central foveal thickness by optical coherence tomography were measured pre- and postoperatively then compared to assess the outcome of surgery.

Results: In all cases intraretinal blood and retinal thickening diminished within 2 months of surgery. Visual acuity improved in all of the central retinal vein occlusion cases and 3/6 branch retinal vein occlusion cases. The decrease in macular thickness was statistically significant (mean postoperative macular thickness $361 \pm 61.1$ versus mean preoperative macular thickness $563.9 \pm 90.0, P=0.001, t$-test). The improvement in BCVA was not statistically significant (mean preoperative BCVA in LogMAR $1.23 \pm 0.29$ versus mean postoperative BCVA in LogMAR $1.06 \pm 0.49, P=0.09, t$-test $)$.

Conclusion: In eyes with macular edema secondary to RVO, pars plana vitrectomy with internal limiting membrane peeling can resolve macular edema, but the improvement in BCVA was not statistically significant in this study.

Keywords: air-fluid exchange, retinal thickening, retinal hypoxia, concomitant retinal ischemia

\section{Introduction}

Retinal vein occlusion (RVO) is the second most common retinal vascular disorder after diabetic retinopathy and is a significant cause of visual morbidity. In these patients macular edema (ME) is a common cause of severe visual loss. The development of ME followed by RVO has been hypothesized to be caused by fluid flux from vessels to tissue according to Starling's law, ${ }^{1,2}$ which is based on the breakdown of the bloodretinal barrier as a result of damage to the tight junctions of capillary endothelial cells, ${ }^{3}$ vitreoretinal adhesion, ${ }^{4}$ and secretion of vasopermeability factors produced in the retina into the vitreous. ${ }^{5,6}$ Observations by Noma et al suggest that in patients with RVO, vascular occlusion induces the expression of vascular endothelial growth factor (VEGF) and interleukin-6 (IL-6), resulting in breakdown of the blood-retinal barrier and increased vascular permeability. ${ }^{6}$ Thus, VEGF and IL-6 may contribute to the development and progression of vasogenic ME in RVO. ME is closely associated with retinal hypoxia, and the degree of hypoxia in the center of the macula corresponds to 
the decrease in visual acuity (VA). If marked hypoxia persists, irreversible structural changes in the macula occur, and the disturbed VA is permanent. If no spontaneous improvement occurs, treatment is mandatory to decrease the duration of edema and prevent photoreceptor damage.

The visual outcome following the natural course of RVO is well documented. Gutman et al found that that chronic ME has a poor prognosis in terms of final VA. Longstanding ME often results in permanent cystic macular changes. ${ }^{7}$

Treatment modalities for ME in RVO are laser treatment, intravitreal and periocular application of steroids, intravitreal injection of VEGF inhibitors, radial optic neurotomy, and vitrectomy techniques.

The present study looked at a new surgical treatment, based on previous hypotheses about the role of the vitreoretinal interface in the pathogenesis of $\mathrm{ME}$, and the popularity of vitrectomy techniques in recent years for the management of ME. Mandelcorn et al reported promising results with macular decompression using vitrectomy and internal limiting membrane (ILM) peeling in cases of severe visual loss from ME due to RVO. ${ }^{8}$ They postulated that removal of the ILM in association with vitrectomy in these cases may allow the edematous retina to decompress by dispersion of retained intraretinal extracellular fluid and blood into the vitreous cavity through the inner retinal surface from which the ILM has been removed.

This report describes the results of macular decompression by vitrectomy and ILM peeling, which was performed in the authors' first nine consecutive cases of severe visual loss due to ME in RVO.

\section{Methods}

This study was a prospective nonrandomized clinical series including a total of nine eyes in nine patients.

Patients were known cases of CRVO and BRVO with ME as confirmed by optical coherence tomography (OCT).

Inclusion criteria were onset of disease between 3 and 9 months before surgery and best-corrected visual acuity (BCVA) of $<20 / 40$. Exclusion criteria were any history of macular photocoagulation, any history of anti-VEGF or corticosteroid injections in the vitreous and any concurrent pathology of the eye that decreased vision.

The study was explained to all the patients and all patients signed consent forms.

A complete preoperative examination with retinal color photography and fluorescein angiography was carried out.
Retinal thickness was measured using OCT. A standard three-port pars plana vitrectomy was carried out. All the surgeries were performed by the same surgeon. If there was no spontaneous posterior vitreous detachment, the preretinal vitreous cortex was removed from the retinal surface (posterior-vitreous-detachment formation). After air-fluid exchange, injection of $0.1 \mathrm{~mL}$ of $2.5 \mathrm{mg} / \mathrm{mL}$ indocyanine green dye (ICG) solution (Akom, Inc, Buffalo Grove, IL) was made into the vitreous cavity over the macula and allowed to act for 30 seconds to stain the ILM. The excess dye was removed using a vitrectomy suction cutter. The ICG-stained ILM was then grasped with vitreous forceps and peeled away from the inner retinal surface over the macular area to a point just outside the foveal avascular zone. An air-fluid exchange was carried out with postoperative prone positioning of the patient for 48 hours so that egress of extracellular fluid and blood from the inner retina could be facilitated using a "squeegee" mechanism similar to pneumatic displacement of submacular hemorrhage. ${ }^{9-13}$

For each patient, the first postoperative evaluation was done 1 week after surgery to check for possible complications, and the last examination to evaluate the final outcome of surgery was performed 2 months postoperatively. In this last visit retinal thickness was measured using OCT and fluorescein angiography was carried out.

\section{Results}

Nine eyes from three male and six female patients were included in the study. Table 1 summarizes all pre- and postoperative data.

There were no complications during surgery or in the follow-up period.

According to fundus fluorescein angiography (FFA) findings, five cases were ischemic and four cases were nonischemic. There were three CRVO and six BRVO cases.

The time from initial onset of RVO to surgical intervention ranged from 3 to 9 months (mean 5.3 months). Preoperative BCVA ranged from 20/100 to 20/800, and preoperative foveal thickness ranged from 411 to $701 \mu \mathrm{m}$ (mean 563.9 \pm 90.0).

Two months after surgery, the BCVA of all CRVO cases improved, but only half of the BRVO cases gained better VA.

There was a statistically significant decrease of macular thickness (postoperative mean macular thickness $361 \pm 61.1$, $P=0.001, t$-test). 
Table I Pre- and postoperative patient data

\begin{tabular}{llllllll}
\hline Case & $\begin{array}{l}\text { Perfusion statue: } \\
\text { ischemic (I) } \\
\text { or not (N) }\end{array}$ & $\begin{array}{l}\text { Duration of } \\
\text { symptoms } \\
\text { (months) }\end{array}$ & Type & $\begin{array}{l}\text { Preoperative } \\
\text { foveal thickness } \\
(\mu \mathrm{m})\end{array}$ & $\begin{array}{l}\text { Postoperative } \\
\text { foveal thickness } \\
(\mu \mathrm{m})\end{array}$ & $\begin{array}{l}\text { Preoperative } \\
\text { BCVA } \\
\text { (logMAR) }\end{array}$ & $\begin{array}{l}\text { Postoperative } \\
\text { BCVA } \\
\text { (logMAR) }\end{array}$ \\
\hline I & I & 6 & BRVO & 411 & 331 & 1.3 & 1.3 \\
2 & I & 4 & BRVO & 566 & 422 & 1.3 & 1.6 \\
3 & $\mathrm{~N}$ & 4 & CRVO & 612 & 421 & 1.0 & 0.7 \\
4 & $\mathrm{~N}$ & 7 & BRVO & 456 & 411 & 1.0 & 0.7 \\
5 & $\mathrm{I}$ & 4 & BRVO & 580 & 299 & 1.3 & 0.7 \\
6 & $\mathrm{I}$ & 7 & BRVO & 542 & 441 & 1.6 & 1.6 \\
7 & $\mathrm{~N}$ & 3 & CRVO & 701 & 325 & 0.7 & 0.3 \\
8 & $\mathrm{~N}$ & 4 & BRVO & 555 & 302 & 1.6 & 1.6 \\
9 & $\mathrm{I}$ & 9 & CRVO & 652 & 297 & 1.3 & 1.0 \\
\hline
\end{tabular}

Abbreviations: BCVA, best corrected visual acuity; CRVO, central retinal vein occlusion; BRVO, branch retinal vein occlusion.

Visual acuity improved in all of the CRVO cases and three out of six BRVO cases, but the improvement in BCVA was not statistically significant (mean preoperative BCVA in LogMAR $1.23 \pm 0.29$ versus mean postoperative BCVA in LogMAR $1.06 \pm 0.49, P=0.09, t$-test $)$.

When ischemic cases were excluded, improvement of BCVA was still not statistically significant $(P=0.06, t$-test).

\section{Discussion}

The mechanism of visual loss in ME due to RVO is thought to be a combination of interference with photoreceptor stimulation by a thickened, hemorrhagic, and edematous retina in association, in some cases, with ischemic retinal damage due to concomitant retinal ischemia. ${ }^{14-19}$ It was hypothesized that vitrectomy with removal of the ILM would allow the congested, hemorrhagic retina to decompress by facilitating the release of extracellular fluid and blood into the vitreous, which would, in turn, restore normal retinal thickness and intraretinal tissue pressure, reduce opacities within the retina that could interfere with light transmission to photoreceptors, and reduce intraretinal pressure around adjacent retinal venules and capillaries that would allow these blood vessels to reopen where possible.

Furthermore, by performing a vitrectomy, sequestered cytokines such as IL-6 and VEGF can be removed from the eye, so their adverse effects can be eliminated.

The vitrectomy performed during this intervention probably improved preretinal oxygen tension ${ }^{2,20,21}$ and, secondarily, may have decreased levels of VEGF. Removal of the ILM might have resulted in decompression of the ME and a further improvement in preretinal oxygen tension., ${ }^{8,22}$ Vasoconstriction stimulated by increased oxygen tension might have reduced hydrostatic vessel pressure, thus decreasing edema.
The results showed that 2 months after surgery, retinal thickness decreased and in some cases VA improved, but this improvement was not statistically significant.

The decrease of macular thickness observed in our study agrees with nearly all previous studies, ${ }^{8,22-24}$ but the statistically insignificant improvement in BCVA is in contrast with all but one recent study, ${ }^{24}$ and one in the older literature. ${ }^{25}$

Mandelcorn found that intraretinal hemorrhage and retinal thickness diminished within an average of 39 days following vitrectomy and ILM peeling. ${ }^{22}$ In this study, therefore, the last visit for evaluating the outcome of our procedure was scheduled for 2 months after surgery.

In some eyes, decreased retinal thickness and improvement in ME might not have been solely the result of improved physiologic features, but partly the result of inner retinal atrophy secondary to retinal ischemia. This especially might have been the case in those eyes with decreased final BCVA. Retinal atrophy might have been responsible for the apparent anatomic improvement on OCT and may account for the lack of a statistically significant corresponding improvement in BCVA.

Even when ME resolves, VA recovery may be limited by photoreceptor layer damage. Ota and associates retrospectively examined eyes with poor VA despite resolved ME after BRVO and demonstrated that damage to the photoreceptor layer of the retina (as defined by lack of visualization of the related high-reflectance band on high-resolution OCT) correlated with poorer final VA. ${ }^{26}$

A relatively small number of nonrandomized consecutive cases were examined in this study, and without a control group this improved anatomic outcome cannot be compared with the natural history of the disease except through comparisons with published data. 
In the Mandelcorn ${ }^{22}$ and Liang et $\mathrm{al}^{23}$ studies, and in the present study, there was no difference in outcome between ischemic and nonischemic cases. Ischemia was evaluated with FFA, but according to Hayreh, ${ }^{27}$ this method of defining ischemia has been criticized because it provides a reliable evaluation of retinal capillary perfusion in only approximately $50 \%-60 \%$ of cases. Combined information from the assessment of relative afferent pupillary defects and electroretinography has been proposed as a superior method of evaluation that is able to differentiate ischemic from nonischemic CRVO in $97 \%$ of cases. Eyes in the present study, classified as nonischemic by FFA criteria, actually may have had more severe disease, and more cases of ischemic RVO might have been detected if they had been examined using alternative methods.

One of the pitfalls in the present study, in comparison with Mandelcorn and Nrusimhadevara, ${ }^{8}$ was that in some of the authors' surgeries, ILM peeling was not as complete as theirs. They peeled the ILM beyond the arcades, but in two cases in this study, the authors peeled the ILM only at the macula, and it seems that was insufficient for the drainage of fluid out of the retina (cases 1 and 6).

Another issue of concern is the retinal toxicity of ICG. ${ }^{28}$ Although using a chromovitrectomy technique for ILM peeling is inevitable, clear-cut safety profiles for the different dyes used in chromovitrectomy have not yet been established. ${ }^{29}$

Finally, in this study, the duration of symptoms for all cases was more than 3 months. Whether early intervention is advantageous to the final outcome was not able to be evaluated in this study.

\section{Conclusion}

According to this and previous studies, pars plana vitrectomy with ILM peeling can be one method for decreasing ME due to RVO but, because of the multiple possible causes for decreased VA in RVO (such as photoreceptor ischemia and atrophy), it is suggested that a larger randomized controlled trial with precise case selection using appropriate imaging and electrophysiologic techniques be undertaken. Surgery should also be performed as soon as possible after diagnosis, before irreversible photoreceptor damage occurs.

\section{Disclosure}

The authors report no conflicts of interest in this work.

\section{References}

1. Arnarsson A, Stefansson E. Laser treatment and the mechanism of edema reduction in branch retinal vein occlusion. Invest Ophthalmol Vis Sci. 2000;41(3):877-879.
2. Stefansson E. The therapeutic effects of retinal laser treatment and vitrectomy. A theory based on oxygen and vascular physiology. Acta Ophthalmol Scand. 2001;79(5):435-440.

3. Silva RM, Faria de Abreu JR, Cunha-Vaz JG. Blood-retina barrier in acute retinal branch vein occlusion. Graefes Arch Clin Exp Ophthalmol. 1995;233(11):721-726.

4. Saika S, Tanaka T, Miyamoto T, Ohnishi Y. Surgical posterior vitreous detachment combined with gas/air tamponade for treating macular edema associated with branch retinal vein occlusion: Retinal tomography and visual outcome. Graefes Arch Clin Exp Ophthalmol. 2001;239(10):729-732.

5. Aiello LP, Avery RL, Arrigg PG, et al. Vascular endothelial growth factor in ocular fluid of patients with diabetic retinopathy and other retinal disorders. N Engl J Med. 1994;331(22):1480-1487.

6. Noma H, Minamoto A, Funatsu H, et al. Intravitreal levels of vascular endothelial growth factor and interleukin- 6 are correlated with macular edema in branch retinal vein occlusion. Graefes Arch Clin Exp Ophthalmol. 2006;244(3):309-315.

7. Gutman FA. Macular edema in branch retinal vein occlusion: prognosis and management. Trans Sect Ophthalmol Am Acad Ophthalmol Otolaryngol. 1977;83(3 Pt 1):488-493.

8. Mandelcorn MS, Nrusimhadevara RK. Internal limiting membrane peeling for decompression of macular edema in retinal vein occlusion: a report of 14 cases. Retina. 2004;24(3):348-355.

9. Hassan AS, Johnson MW, Schneiderman TE, et al. Management of submacular hemorrhage with intravitreous tissue plasminogen activator injection and pneumatic displacement. Ophthalmology. 1999;106(10): 1900-1906.

10. Hesse L, Kroll P. Pneumatic displacement of submacular hemorrhage. Ophthalmology. 2000;107(12):2119-2120.

11. Johnson MW. Pneumatic displacement of submacular hemorrhage: author's reply. Ophthalmology. 2000;107(12):2120.

12. Johnson MW. Pneumatic displacement of submacular hemorrhage. Curr Opin Ophthalmol. 2000;11(3):201-206.

13. Averbukh E, Devenyi RG, Lam WC, Berger AR. Pneumatic displacement of submacular hemorrhage. Ophthalmology. 2000;107:2118-2119.

14. The Branch Vein Occlusion Study Group. Argon laser photocoagulation for macular edema in branch vein occlusion. Am J Ophthalmol. 1984;98(3):271-282.

15. Gandorfer A, Messmer EM, Ulbig MW, Kampik A. Resolution of diabetic macular edema after surgical removal of the posterior hyaloid and the inner limiting membrane. Retina. 2000;20(2):126-133.

16. Quinlan PM, Elman MJ, Bhatt AK, Mardesich P, Enger C. The natural course of central retinal vein occlusion. Am J Ophthalmol. 1990;110(2):118-123.

17. Chen JC, Klein ML, Watzke RC, Handelman IL, Robertson JE. Natural course of perfused central retinal vein occlusion. Can J Ophthalmol. 1995;30(1):21-24.

18. Hayreh SS, Hayreh MS. Hemi-central retinal vein occlusion. Pathogenesis, clinical features, and natural history. Arch Ophthalmol. 1980;98(9):1600-1609.

19. Suzuma K, Kita M, Yamana T, et al. Quantitative assessment of macular edema with retinal vein occlusion. Am J Ophthalmol. 1998;126(3): 409-416.

20. Leizaola-Fernandez C, Suarez-Tata L, Quiroz-Mercado H, et al. Vitrectomy with complete posterior hyaloid removal for ischemic central retinal vein occlusion: series of cases. BMC Ophthalmol. 2005;5:10.

21. Tachi N, Hashimoto Y, Ogino N. Vitrectomy for macular edema combined with retinal vein occlusion. Doc Ophthalmol. 1999;97(3-4):465-469.

22. Mandelcorn M. Vitrectomy with surgical macular decompression by internal limiting membrane removal. Can J Ophthalmol. 2007;42(4):626.

23. Liang XL, Chen HY, Huang YS, et al. Pars plana vitrectomy and internal limiting membrane peeling for macular oedema secondary to retinal vein occlusion: a pilot study. Ann Acad Med Singapore. 2007;36(4): 293-297. 
24. DeCroos FC, Shuler RK Jr, Stinnett S, et al. Pars plana vitrectomy, internal limiting membrane peeling, and panretinal endophotocoagulation for macular edema secondary to central retinal vein occlusion. Am J Ophthalmol. 2009;147(4):627-633. e1.

25. Radetzky S, Walter P, Fauser S, Koizumi K, Kirchhof B, Joussen AM. Visual outcome of patients with macular edema after pars plana vitrectomy and indocyanine green-assisted peeling of the internal limiting membrane. Graefes Arch Clin Exp Ophthalmol. 2004;242(4): 273-278.

26. Ota M, Tsujikawa A, Murakami T, et al. Association between integrity of foveal photoreceptor layer and visual acuity in branch retinal vein occlusion. Br J Ophthalmol. 2007;91(12):1644 -1649.
27. Hayreh SS. Prevalent misconceptions about acute retinal vascular occlusive disorders. Prog Retin Eye Res. 2005;24(4):493-519.

28. Ferencz M, Somfai GM, Farkas A, et al. Functional assessment of the possible toxicity of indocyanine green dye in macular hole surgery. Am J Ophthalmol. 2006;142(5):765-770.

29. Farah ME, Maia M, Rodrigues EB. Dyes in ocular surgery: principles for use in chromovitrectomy. Am J Ophthalmol. 2009;148(3): $332-400$.

\section{Publish your work in this journal}

Clinical Ophthalmology is an international, peer-reviewed journal covering all subspecialties within ophthalmology. Key topics include: Optometry; Visual science; Pharmacology and drug therapy in eye diseases; Basic Sciences; Primary and Secondary eye care; Patien Safety and Quality of Care Improvements. This journal is indexed on

Submit your manuscript here: http://www.dovepress.com/clinical-ophthalmology-journal

\section{Dovepress}

PubMed Central and CAS, and is the official journal of The Society of Clinical Ophthalmology (SCO). The manuscript management system is completely online and includes a very quick and fair peer-review system, which is all easy to use. Visit http://www.dovepress.com/ testimonials.php to read real quotes from published authors. 